\title{
Erratum to: Genome-wide copy number variation association study suggested VPS13B gene for osteoporosis in Caucasians
}

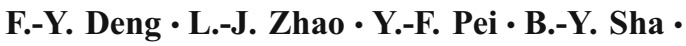 \\ X.-G. Liu • H. Yan • L. Wang • T.-L. Yang • \\ R. R. Recker • C. J. Papasian • H.-W. Deng
}

Published online: 10 April 2010

(C) International Osteoporosis Foundation and National Osteoporosis Foundation 2010

\section{Erratum to: Osteoporos Int (2010) 21:579-587 \\ DOI 10.1007/s00198-009-0998-7}

Table 3 unfortunately contained errors. The correct version is given here.

Table 3 Association between CNV_084 and bone phenotypes in the sample

Presented are mean (SD) [observation number]. In the total sample, age and gender were adjusted. In the genderstratified analyses, age was adjusted as a covariant. Marked in bold are data that remained significant after Bonferroni correction

\begin{tabular}{|c|c|c|c|c|c|}
\hline \multirow[t]{2}{*}{ Phenotype } & \multicolumn{2}{|l|}{ Phenotypic value } & \multicolumn{3}{|l|}{$\mathrm{P}$ value } \\
\hline & $\mathrm{CNV}$ state $=1$ & $\mathrm{CNV}$ state $=2$ & Total & Female & Male \\
\hline SPN BMD & $1.18(0.22)[16]$ & $1.03(0.16)$ [965] & 0.0001 & 0.0559 & 0.0003 \\
\hline Hip BMD & $1.09(0.20)[16]$ & $0.97(0.15)$ [963] & 0.0002 & 0.0096 & 0.0071 \\
\hline FN BMD & $0.92(0.20)[16]$ & $0.81(0.14)$ [952] & 0.0001 & 0.0032 & 0.0103 \\
\hline CT & $0.18(0.04)[16]$ & $0.15(0.03)$ [958] & 0.0001 & 0.0029 & 0.0042 \\
\hline CSA & $3.13(0.77)[16]$ & $2.83(0.64)$ [958] & 0.0030 & 0.0150 & 0.0510 \\
\hline BR & $10.71(2.92)[16]$ & $12.04(2.73)[958]$ & 0.0170 & 0.1140 & 0.0710 \\
\hline
\end{tabular}

The online version of the original article can be found at http://dx.doi. org/10.1007/s00198-009-0998-7.

F.-Y. Deng · Y.-F. Pei · T.-L. Yang • C. J. Papasian •

H.-W. Deng $(\triangle)$

School of Medicine, University of Missouri-Kansas City,

Kansas City, MO 64108, USA

e-mail: dengh@umkc.edu

F.-Y. Deng

e-mail: dengfe@umkc.edu

L.-J. Zhao · R. R. Recker

Osteoporosis Research Center, Creighton University,

Omaha, NE 68131, USA
Y.-F. Pei $\cdot$ X.-G. Liu $\cdot$ H. Yan $\cdot$ L. Wang $\cdot$ H.-W. Deng The Key Laboratory of Biomedical Information Engineering of Ministry of Education and Institute of Molecular Genetics, School of Life Science and Technology, Xi'an Jiaotong University, Xi'an, Shannxi 710049 ,

People's Republic of China

B.-Y. Sha $\cdot$ H.-W. Deng

Laboratory of Molecular and Statistical Genetics,

College of Life Sciences, Hunan Normal University,

Changsha, Hunan 410081, People's Republic of China 